\title{
O CARÁTER PÚBLICO DOS ESPAÇOS LIVRES DA CASA DAS ONZE JANELAS E DO FORTE DO CASTELO EM BELÉM, PARÁ ${ }^{1}$
}

\author{
Juliana Vasconcelos Moreira² \\ José Júlio Ferreira Lima ${ }^{3}$
}

DOI: 10.5752/P.2316-1752.2018v25n37p52

\begin{abstract}
Resumo
A Casa das Onze Janelas e Forte do Castelo (COJFC) localizam-se no núcleo inicial de Belém, PA, cujas edificações e espaços públicos receberam um projeto restaurativo e de requalificação urbana em 2002. O projeto criou espaços livres próximos a COJFC, e sua gestão os submete a regras específicas, como restrições de acesso e comportamento. O artigo objetiva analisar o caráter público desses espaços,
\end{abstract}

\footnotetext{
1. Este artigo toma por base investigação presente em pesquisa de mestrado de Juliana Vasconcelos Moreira, no Programa de Pós-graduação em Arquitetura e Urbanismo (PPGAU) da Universidade Federal do Pará (UFPA), sob orientação do Prof. PhD. José Júlio Lima.

2. Arquiteta e Urbanista pela UFPA e mestre pelo Programa de Pós-graduação Arquitetura e Urbanismo da UFPA. E-mail: juv.moreira@gmail.com.

3. Arquiteto e Urbanista pela UFPA, mestre em Arquitetura (Universidade de Fukui/ Japão), mestre em Desenho Urbano (Oxford Brookes University/UK) e PhD em Arquitetura (Oxford Brookes University/UK) atualmente professor associadoda Faculdade de Arquitetura e UFPA e professor do seu respectivo Programa de Pós Graduação. E-mail: jjlimaufpa@gmail.com.
} 
com base na percepção dos usuários utilizando questionários. As regras são majoritariamente aceitas, mas tornam confusa a percepção dos usuários sobre o caráter público dos espaços.

Palavras-chave: Espaços públicos. Complexo Feliz Lusitânia. Belém (PA). 


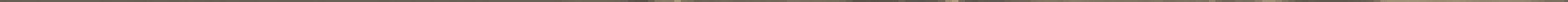

THE PUBLIC CHARACTER OF THE OPEN SPACES AT CASA DAS ONZE JANELAS AND FORTE DO CASTELO IN BELEM, PARA, BRAZIL

\section{Abstract}

The Casa das Onze Janelas and Forte do Castelo (COJFC) are located in the original nucleus of Belém, PA, which buildings and public spaces received a restoration and urban rehabilitation project in 2002. The project created open spaces close to ts them to rers' per-

Keywords: Public spaces. Feliz Lusitânia Complex, Belém (PA).

Palabras-claves: Espacios Feliz Lusitânia, Belém (PA) 


\section{Introdução}

Entre 1997 e 2002 foram realizadas, pelo Governo do Estado do Pará, por meio da Secretaria de Cultura (SECULT), intervenções no local de fundação da cidade de Belém, conhecido a partir de então como Complexo Feliz Lusitânia. Essas intervenções incluíram a criação de espaços livres e a restauração de edifícios históricos, como a Igreja de Santo Alexandre, onde se localiza o Museu de Arte Sacra, um casario adjacente, o Forte do Presépio, que abriga o Museu do Encontro, um antigo Hospital Militar que passou a ser denominado Casa das Onze Janelas, com galerias de arte e um restaurante. Posteriormente foi realizada também a restauração da Catedral Metropolitana de Belém, obra entregue em 2008.

O Projeto Feliz Lusitânia baseia-se em uma corrente de planejamento urbano conhecida como planejamento estratégico, que tem como inspiração o planejamento empresarial ou "empreendedorismo urbano" (HARVEY, 2005). Acredita-se que essa tendência tenha sido reflexo do que, segundo Vargas e Castilho (2006), estava sendo aplicado no planejamento urbano de várias metrópoles no mundo entre 1980 e 2000. Segundo Harvey (2005), as intervenções do período visavam ao city marketing (VAINER, 2000), tornando as cidades mais "vendáveis" e competitivas. 
Parte da estratégia de tornar as cidades mais atrativas inclui a participação de organizações privadas na administração da coisa pública (CASTELLS E BORJA, 1996); em Belém, isso foi praticado a partir de contratos com entidades paraestatais, as Organizações Sociais. Organizações Sociais, segundo Di Pietro (2012, p. 565), se constituem de "pessoa jurídica de direito privado, sem fins lucrativos, instituída por iniciativa de particulares e que recebe delegação do Poder público, mediante contrato de gestão, para desempenhar serviço público de natureza social." Seguindo a cartilha do city marketing, as intervenções feitas em Belém ocuparam edifícios antigos e estruturas portuárias subutilizadas em áreas históricas, transformando-as em espaços de consumo visual e real, como restaurantes, museus, teatro, lojas e cinemas. O público alvo consiste principalmente em turistas e investidores externos, ou, pode-se dizer, usuários "solventes" (CASTELLS E BORJA, 1996). Outros projetos similares do Governo do Estado também foram executados na mesma época, como a Estação das Docas, inaugurada em 2000, e o Parque Zoobotânico Mangal das Garças, inaugurado em 2005.

O Complexo Feliz Lusitânia se localiza no bairro da Cidade Velha, o primeiro da cidade, que, junto com o bairro da Campina, formam o Centro Histórico de Belém (CHB). Segundo SECULT (2006), o projeto, que incluiu edifícios tombados e áreas livres somando aproximadamente $25.000 \mathrm{~m}^{2}$ 
(Figura 1), objetivou retomar referenciais históricos, sociais e econômicos do Pará por meio das dimensões urbanísticas, arquitetônicas e paisagísticas da área. A obra sobre o projeto também afirma que o objetivo do projeto foi "promover uma refuncionalização dos prédios, com usos mais compatíveis com a sociedade atual."

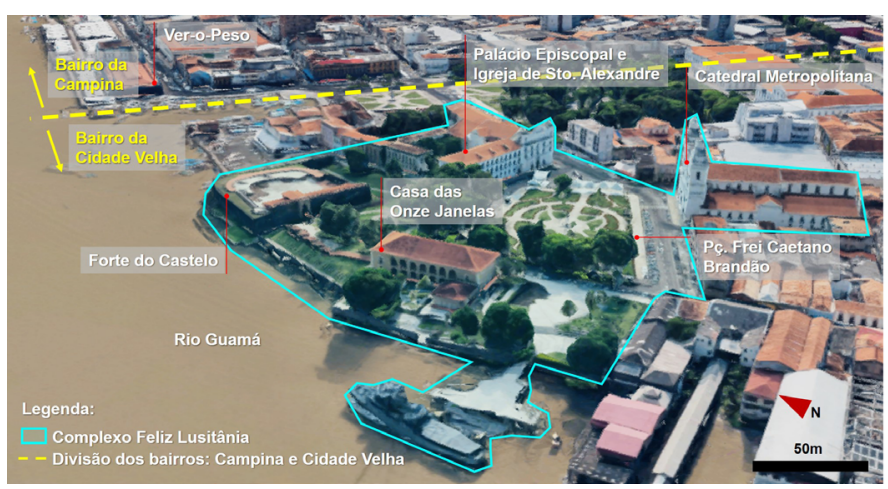

Figura 1 | Trecho do bairro da Cidade Velha onde se localiza o Complexo Feliz Lusitânia Destaque para os edifícios e a Praça Frei Caetano Brandão que o compõem.

Fonte: Google, 2017. Adaptado pela autora

Até a intervenção de 2002, a Casa das Onze Janelas e o Forte do Castelo eram de propriedade da Marinha do Brasil e abrigavam o Clube do Círculo Militar. O objeto de estudo deste artigo se concentra nos espaços livres, ou seja, espaços não confinados, adjacentes a esses dois edifícios, transformados em ambientes de permanência e passeio 
pelo projeto executado (Figura 2). Após a intervenção, esses espaços livres ganharam um caráter museológico e de contemplação da natureza.

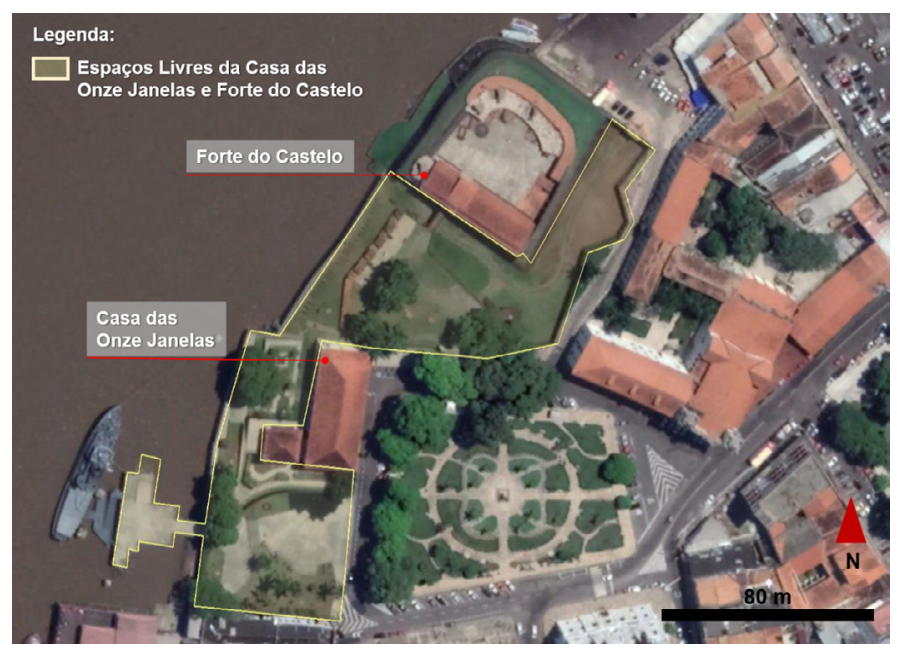

Figura 2 | Espaços livres da Casa das Onze Janelas e do Forte do Castelo, objeto de estudo da pesquisa.

Fonte: Google Earth, 2018. Adaptado

Os espaços livres da Casa das Onze Janelas e do Forte do Castelo são integrados entre si e ao seu entorno, porém guardam algumas diferenças com relação a outros espaços livres da cidade, devido ao fato de não serem geridos pela gestão pública municipal e, sim, pela gestão estadual 
no modelo de publicização. Publicização é um processo no qual serviços originalmente de execução da administração pública passam a ser geridos por uma Organização Social no campo da prestação de serviços sociais e de infraestrutura. A gestão feita pela Secretaria de Cultura do Estado impõe algumas regras de utilização dos espaços pouco comuns em espaços livres urbanos, como horários de entrada e saída, proibição de entrada de animais de estimação, de moradores de rua e vendedores ambulantes, entre outras, além de garantir serviços privados de coleta de lixo, limpeza e segurança. O uso controlado e os serviços privados encontrados nos espaços abertos da Casa das Onze Janelas e do Forte do Castelo, que não ocorrem no espaço público adjacente mesmo com a integração entre ambos, foi o que justificou a discussão a respeito de seu caráter público ou privado.

Constitui-se como objetivo deste artigo realizar uma discussão sobre os limites e as interfaces entre as naturezas público e privado dos espaços livres da Casa das Onze Janelas e do Forte do Castelo com base nas intenções projetuais e regras de utilização e funcionamento. Tem-se como referência das análises as consequências da gestão em curso e a percepção de frequentadores daqueles espaços. Para isso, este artigo, após esta introdução, apresenta a metodologia aplicada, seguido de uma apresentação dos espaços em estudo e duas sessões de análise. A primeira, 
sobre o que os limiares do que é considerado público e privado nos espaços, complementada por uma análise da percepção de usuários no que diz respeito ao caráter público/privado desses espaços, como consequência do que se considerou como regras de utilização dos espaços a partir de sua gestão.

\section{Metodologia}

A metodologia da pesquisa foi dividida em duas etapas. A primeira contou com pesquisa na literatura sobre espaços públicos/privados, atendendo ao primeiro objetivo específico. A segunda consistiu na aplicação de questionários contendo 15 questões, sendo $8 \mathrm{com}$ respostas fechadas e 7 com respostas abertas, atendendo ao segundo objetivo específico. Foram aplicados ao todo 73 questionários em seis dias no intervalo de aproximadamente um mês (08/11/15 a 05/12/15), em dias úteis e finais de semana, pela manhã e pela tarde. Considerando que a diversidade dos usuários é um fator determinante para a discussão do caráter público dos espaços urbanos (CALDEIRA, 2000), os questionários buscavam traçar um perfil dos entrevistados a partir de dados como: idade, escolaridade, ocupação e local de moradia. Tratavam também da frequência com que eles visitam aqueles espaços e de seus objetivos na visita em questão.

Os questionários indagavam também sobre pontos posi- 
tivos e negativos do objeto de estudo na percepção dos frequentadores, e como eles entendem o conceito de espaço público. Em seguida, havia perguntas sobre as regras impostas: se os frequentadores estavam cientes das regras, se julgavam cada regra como negativa ou positiva e por quê. Por fim, indagava se o entrevistado considerava o objeto de estudo como um espaço público. Os resultados foram tabulados e organizados em frequências para identificação de percepções quanto a restrições de uso e permanência nos espaços estudados.

\section{Os espaços livres da Casa das Onze Janelas e do Forte do Castelo e sua gestão}

Os espaços livres da Casa das Onze Janelas e do Forte do Castelo, doravante COJFC, foram criados a partir de uma intervenção do Governo Estadual finalizada em 2002. A intervenção explorou atributos paisagísticos do espaço, utilizando-se de vegetação, da proximidade com o rio Guamá e de artefatos artísticos e históricos. Em 1995 foi iniciado o processo de alienação dos espaços referentes à COJFC, anteriormente de uso da Marinha do Brasil, para a execução do projeto. Os dois lotes contavam com quadra de esportes, a sede social do clube do Círculo Militar, restaurantes e outras benfeitorias, demolidas em prol da criação dos novos espaços (Figura 3 a e b). Dentre essas benfeitorias 
demolidas, havia um muro construído ainda no século XIX, que demarcava o limite entre o espaço público e o espaço privado, cuja demolição foi alvo de controvérsia por arquitetos da cidade. A demolição parcial do muro se deu sob a justificativa de "abrir uma janela da praça [Frei Caetano Brandão] para o Rio" (SECULT, 2006).
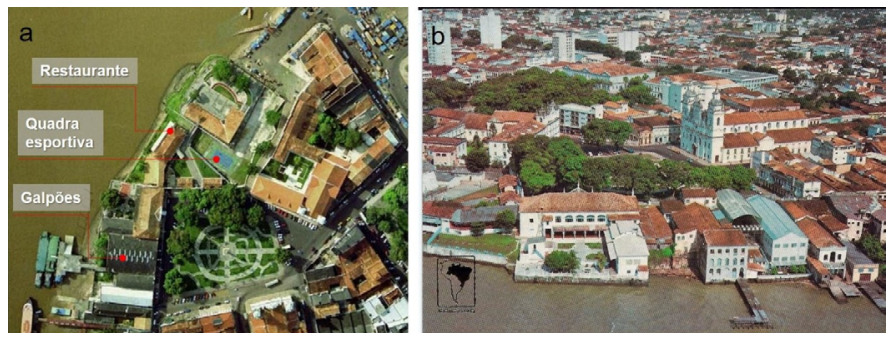

Figura 3 | (a) Vista aérea da situação anterior ao projeto, quando os lotes ainda eram de posse da Marinha do Brasil; (b) Cartão Postal com imagem da área do objeto de estudo antes das intervenções de data desconhecida.

Fonte: (a) SEURB/CODEM, adaptada pela autora. Base cartográfica, Belém 2000/Ortoleves; (b) Editora Edicard, sem data

Os espaços livres da COJFC são constituídos pelos ambientes de permanência e passeio criados pelo projeto de revitalização conduzido pela SECULT. Os ambientes são integrados entre si e ocupam toda a área disponível nas adjacências dos dois edifícios (Figura 4). Segundo SECULT (2006), os ambientes são: o Recanto das Amazonas (01), o Anfiteatro (02), o Píer (03), a Esplanada do Guamá (04), o Mirante da Lembrança (05), a Bateria Baixa (06) de canhões 
e o Fosso do Forte (07). Ainda segundo SECULT (2006), tais espaços deveriam funcionar como locais de contemplação, não apenas do rio, mas de todo o conjunto restaurado.

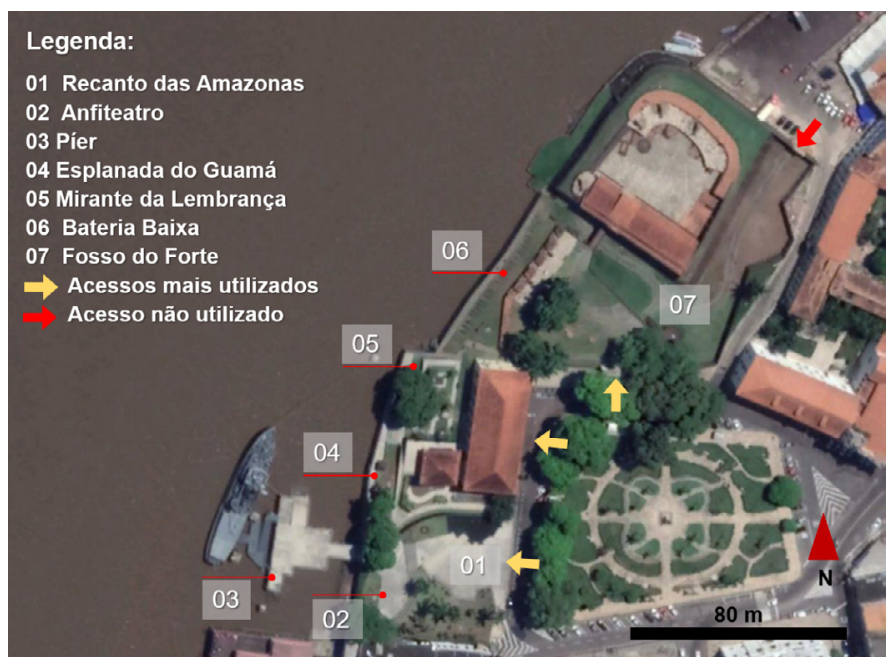

Figura 4 | Ambientes e acessos criados pelo projeto nos espaços livres da Casa das Onze Janelas e do Forte do Castelo. Fonte: Google Earth, 2018. Adaptado

Existem quatro acessos aos espaços livres da COJFC, porém nem todos podem ser utilizados devido à presença de fechamentos (Figura 5). Os acessos mais utilizados são o arco que leva ao Forte (b), localizado no que restou do muro demolido, e o Recanto das Amazonas (a), que se integra, 
e até se confunde, com a calçada externa. Além desses, também é possível acessar o espaço livre por dentro da Casa das Onze Janelas (d), cujas portas de um lado a outro permanecem abertas conforme o funcionamento das galerias de arte. Há também um portão, localizado no Fosso do Forte (c), voltado para o Complexo do Ver-o-Peso, que, entretanto, fica permanentemente fechado. Apesar dos acessos mais utilizados serem integrados às calçadas $e$ não apresentarem nenhum tipo de elemento de vedação, como grades e portas, o funcionamento dos espaços livres da Casa das Onze Janelas e do Forte do Castelo se dá das $06 \mathrm{~h}$ às $23 \mathrm{~h}$, diariamente. Durante a madrugada, é estendida uma corrente nos limites dos lotes, de modo a evitar a entrada de visitantes. 

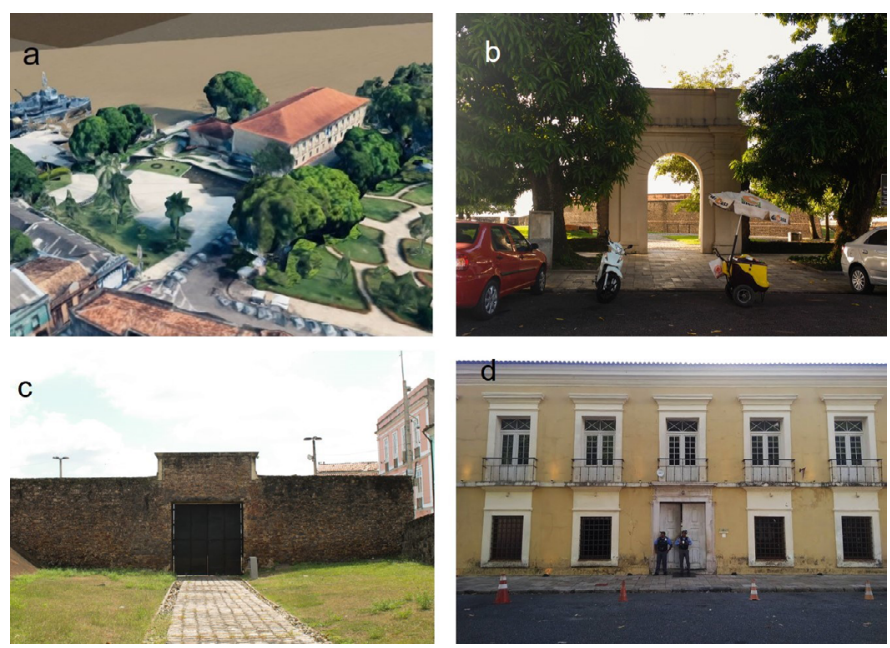

Figura 5 | Acessos criados pelo projeto: (a) Vista aérea do acesso pelo Recanto das Amazonas; (b) Acesso pelo Arco do Forte; (c) Portão permanentemente fechado; (d) Acesso pela Casa Das Onze Janelas.

Fonte: (a) Imagem aérea - Google, 2018. Imagens ( b), (c) e (d) - Autora, 2015

Com relação aos ambientes do projeto (Figura 6), o Recanto das Amazonas (a), um dos principais acessos é uma área ampla e aberta que conta com um espelho d'água e chafarizes e se confunde com calçada. O Píer dá acesso a Corveta Museu Solimões, um museu da Marinha, que se encontra dentro de uma corveta ancorada, aberta à visitação. O Anfiteatro (b), a Esplanada do Guamá, o Mirante da Lembrança (c) e a Bateria Baixa (d) são espaços de contemplação e passeio, contando com bancos e arborização. 

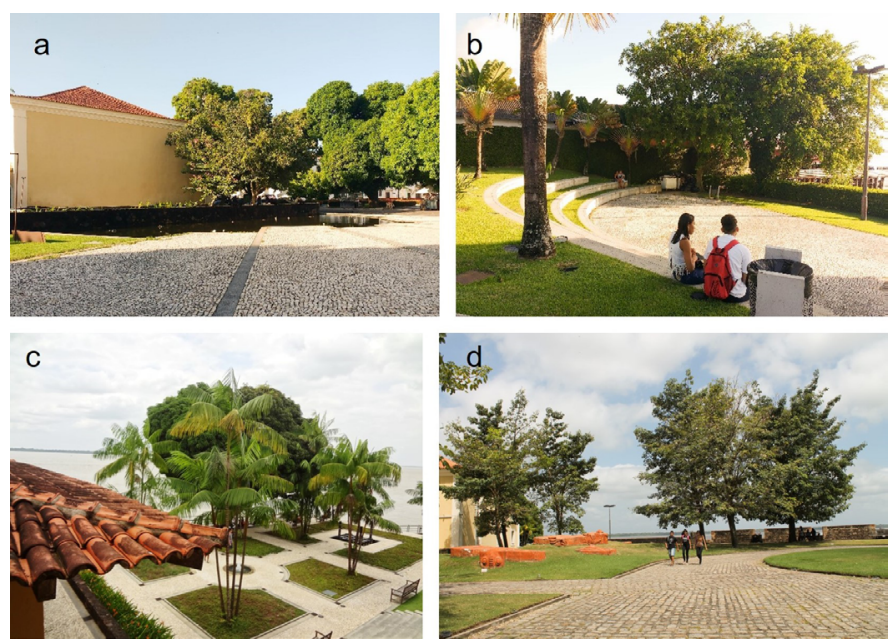

Figura 6 | Ambientes criados pelo projeto: (a) Recanto das Amazonas, na lateral na Casa das Onze Janelas onde há um espelho d'água; (b) Anfiteatro; (c) Mirante da Lembrança;

(d) Bateria Baixa de canhões ao fundo

Fonte: Autora, 2015

O Fosso do Forte é considerado um "espaço paisagístico de excelência" (SECULT, 2006), acessível principalmente por uma escada metálica. O Fosso conta com ampla área gramada (Figura 7 a), que, devido à proibição de acesso à grama, restringe em grande medida a área de passeio dos frequentadores. A área pavimentada na qual o público pode caminhar tem um traçado estreito e sinuoso, sendo interrompida pelo portão (Figura 7 b), constantemente fechado, que daria acesso à Feira do Açaí (parte do Complexo do Ver-o-Peso). 


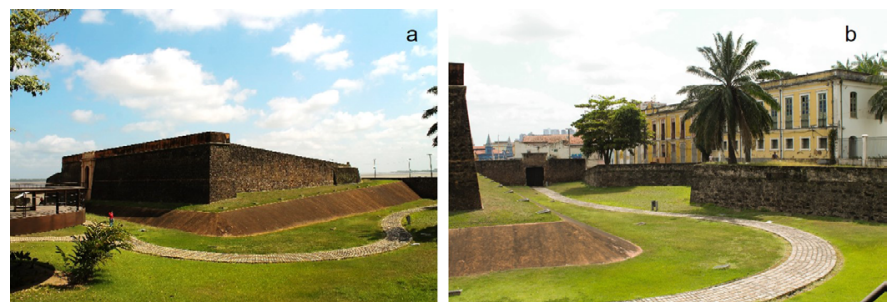

Figura 7: Imagens do Fosso do Forte: (a) Vista geral do Fosso com ampla área gramada e Forte ao fundo; (b) Caminho pavimentado interrompido pelo portão

Fonte: Autora, 2015

Foi firmado, como uma das medidas para viabilização da manutenção e gestão da Casa das Onze Janelas, do Forte do Castelo e de espaços livres adjacentes, um contrato de publicização, forma de gestão regularizada no Brasil na década de 1990 (BRASIL, 1995). O Governo do Estado concedeu a administração dos recém-criados espaços a uma Organização Social denominada Pará 2000, também responsável por outros empreendimentos turísticos da cidade, como a Estação das Docas e o Parque Zoobotânico Mangal das Garças. Destaca-se que, diferentemente do Mangal das Garças e da Estação das Docas, os espaços livres da Casa das Onze Janelas e do Forte do Castelo são integrados ao passeio público, sem a presença de grades ou portas nos acessos mais utilizados.

Esses três empreendimentos guardam mais algumas semelhanças além da gestão: todos foram criados como 
atrativos turísticos, contam com serviços privados e regras de funcionamento e utilização. No caso das áreas livres da Casa das Onze Janelas e do Forte do Castelo as regras são: é proibido o contato com o rio Guamá; é proibida a entrada de bicicletas, de animais de estimação, de moradores de rua e de vendedores ambulantes; é proibido deitar ou subir em bancos e pisar ou sentar nas áreas gramadas; a partir das $23 \mathrm{~h}$, estende-se uma corrente no limite do lote e é solicitado aos visitantes que deixem o espaço.

Destaca-se que não há qualquer estratégia projetual que coíba os comportamentos não permitidos: as áreas gramadas são facilmente acessíveis, não há local apropriado para o estacionamento de bicicletas próximo às entradas, não há sinalização que indique a proibição da entrada de animais ou de vendedores ambulantes. As regras são informadas aos frequentadores pelos vigilantes terceirizados que trabalham no local. Na maioria das vezes, essa informação ocorre quando um visitante infringe alguma das regras e é advertido pelo vigilante.

\section{O caráter público/privado do objeto de estudo}

À primeira vista, os espaços livres se confundem com o seu entorno por contarem com acessos amplamente abertos durante o dia, alta visibilidade da rua para o interior do 
lote e até mesmo pelo fato do pavimento do Recanto das Amazonas se estender até o passeio público em um trecho da calçada. Entretanto, ao visitar os espaços, é possível notar que existem diferenças relevantes entre os espaços livres no interior do lote e os espaços fora dele: as ruas, as calçadas e a Praça Frei Caetano Brandão.

Espaços públicos são mais que simples espaços urbanos. O conceito de espaço público carrega consigo o caráter de condicionador da esfera pública: "é onde se dá a interação de indivíduos que, com uma maior ou menor liberdade, expressam seus pontos de vista, articulam suas demandas, negociam seus conflitos, veem e são vistos" (SOUZA, 2008). O espaço público e as suas fronteiras são construídos socialmente, por meio daqueles que o utilizam, com seus conflitos e suas estratégias de entendimento. No momento em que tais fronteiras passam a ser criadas compulsoriamente por instituições como o Estado, ou mesmo - Mercado, o caráter público desses espaços se esvazia (LEITE, 2004).

A restrição de acesso a moradores de rua e vendedores ambulantes, exemplo que ocorre nos espaços livres da COJFC, fere a noção de espaço público, que admite a liberdade de acesso e a possibilidade de criação e desenvolvimento de relações sociais espontâneas. Essa restrição de público, combinada a outras restrições comportamentais, como a 
proibição de acesso às áreas gramadas e do contato direto com o rio, demonstram uma valorização da imagem sobre o uso, tornando-o quase estéril em prol de uma paisagem ideal para o consumo visual.

Conforme declaram seus projetistas e idealizadores em SECULT (2006), havia no projeto uma intenção de transformar os espaços livres da Casa das Onze Janelas e do Forte do Castelo em um espaço museológico. Segundo Choay (2001), é comum a dissimulação, abertamente assumida por promotores privados e públicos, de uma natureza museal em intervenções como a que se tem em análise, sob a justificativa de valorizarem o patrimônio histórico e cultural de porções urbanas. A criação de uma imagem imaculada é essencial para o cumprimento do objetivo de vender um espaço de qualidade superior ao resto da cidade. Entretanto, para isso, devem ser evitadas algumas situações que podem interferir negativamente na paisagem. É o que ocorre no objeto de estudo ao se evitar a presença de animais e de moradores de rua por exemplo; daí a necessidade de criação de regras que possam garantir a estética imaginada para o lugar.

Apesar do objeto de estudo não contar com elementos de vedação, como grades, muros ou sequer portas nos acessos mais utilizados, se assemelha ao que Leite (2007) chama de "enclave fortificado". Os espaços livres da Casa das 
Onze Janelas e do Forte do Castelo contrastam com o seu entorno devido às regras e aos serviços terceirizados. São espaços "à parte da cidade, cuja lógica urbanística se rende ao sofisticado aparato da segurança particular e da vigilância eletrônica de seus espaços privatizados" (LEITE, 2007, p. 20). Tais características são comuns em modelos habitacionais, como condomínios fechados; no caso em questão, entretanto, se revelam em um espaço livre, aberto ao público, ainda que restrinja a entrada de algumas pessoas.

De modo a garantir o cumprimento das regras, há no espaço uma constante vigilância dos frequentadores por parte dos seguranças. Zukin (2000a) descreve essa vigilância constante como uma agudização da assimetria do poder existente nas cidades. Situações como essa definem uma nova maneira de as pessoas se relacionarem entre si e com aquele trecho urbano ou edifício histórico, tornando o espaço uma "paisagem de poder" (ZUKIN, 2000a). No caso em questão, nota-se isso de maneira muito clara na presença de vigilantes fardados e câmeras de segurança.

Segundo Choay (2006), é comum, em "revitalizações" de centros urbanos históricos, o processo de gentrificação ao serem aplicadas estratégias que coíbem direta ou indiretamente o uso dos espaços abertos pela população local, especialmente de baixa renda. Por exemplo, é costumeiro em outros locais da cidade, como no Ver-o-Peso, o banho de rio 
pela população; no objeto de estudo, entretanto, essa prática é proibida, ainda que o projeto intencionasse, em tese, uma reconexão com o rio.

Estratégias de coibição podem incluir limitações físicas, como o fechamento de espaços por meio do uso de grades, correntes e portões; mas também limitações simbólicas, como a venda de produtos voltados para um público de alto padrão ou ainda em casos extremos, ao restringir o acesso de segmentos da sociedade que são encarados como incompatíveis com o projeto do espaço.

A "embalagem" que se dá ao patrimônio histórico urbano tendo em vista o seu consumo cultural, assim como o fato de ser alvo de investimentos do mercado imobiliário de prestígio, tende a excluir dele as populações locais ou não privilegiadas e, com elas, suas atividades tradicionais e modestamente cotidianas. (CHOAY, 2001, p. 226).

Segundo Leite (2004), tais práticas segregacionistas geram formas de sociabilidade efêmeras e superficiais, que muitas vezes se restringem apenas ao consumo visual, o que enfraquece o caráter público desses espaços.

A busca da paisagem "vendável", nesses espaços ditos públicos, acarreta um código de uso implícito que não é compatível com o uso espontâneo e vernacular, gerando uma "higienização social", na qual aqueles que não mais se 
enquadram nas novas premissas do espaço são excluídos. Essa disneyficação da cidade (ZUKIN, 2000b) se traduz na estetização dos espaços da cidade por meio de um controle social e de estratégias de segurança.

Com restrições impostas assimetricamente por setores sociais dominantes, em busca de uma ordem moral que contribua para uma imagem desejada, substitui-se a noção do lugar socialmente construído por um lugar a ser consumido como uma utopia. Há uma ideologia na criação desses espaços, ao venderem uma paisagem artificializada de uma cidade em que tudo funciona, e, ao priorizar o uso do espaço por pessoas compatíveis com a imagem idealizada, tornando-se muitas vezes marcos espaciais da segregação na cidade. Ainda assim, após essa análise do objeto de estudo com base na literatura, se considerou indispensável identificar a avaliação do público frequentador com relação às regras e funcionamento dos espaços, e a percepção quanto ao seu caráter público/privado.

\section{Resultados e discussões}

A primeira parte dos questionários aplicados a frequentadores dos espaços buscava traçar os perfis dos visitantes, coletar dados que permitissem identificar quem são as pessoas que efetivamente usam os espaços livres da COJFC e qual o interesse delas ali. Dentre os 73 entrevistados, 
33 eram jovens estudantes entre 14 e 29 anos (45,21\%); dos 40 não estudantes restantes (54,79\%), com idades variando entre 18 e mais de 50 anos, a maioria apresentava ensino médio completo em diversas ocupações.

Sobre a frequência de visitas, 17 dos 35 usuários que alegaram frequentar o espaço no mínimo mensalmente vêm de bairros periféricos distantes, alguns onde há focos de pobreza e carência urbana, ou mesmo de outros municípios. Dos 7 moradores do CHB e entorno, 3 entrevistados disseram visitar o espaço semanalmente/quinzenalmente. A metade dos visitantes abordados (37 pessoas) alegou que vai aos espaços livres da COJFC em busca de contemplação e lazer; mas houve também os que vão encontrar amigos (9 pessoas), trabalhar — fotógrafos e jornalistas ou fazer pesquisas escolares, no caso dos mais jovens (6 pessoas). Apenas 8 dentre os entrevistados eram turistas ou estavam levando turistas para conhecer o espaço.

A pergunta sobre os aspectos positivos e negativos era aberta, de modo que cada entrevistado poderia responder mais de uma característica. O aspecto positivo mais citado, aparecendo em $54,27 \%$ das respostas, tratava de aspectos do ambiente natural, como a paisagem, o vento, as áreas sombreadas, etc. A segurança do espaço foi o segundo ponto positivo mais citado, aparecendo em 12,40\% das respostas, seguido pela tranquilidade e pela qualidade do 
espaço preservado.

Das pessoas abordadas, $23,46 \%$ não apontou nenhum ponto negativo nos espaços livres da COJFC. O ponto negativo mais citado não tratava do objeto de estudo da pesquisa, mas do seu entorno: a insegurança da Praça Frei Caetano Brandão e vias adjacentes foi citada em $17,28 \%$ das respostas. Aspectos menos citados foram a falta de informações históricas, de opções de alimentação, problemas com insegurança, poluição e problemas com a manutenção da infraestrutura dos espaços. Uma pessoa citou o comportamento dos vigilantes e, outra, as regras de utilização, como pontos negativos.

Sobre a legitimação das regras e restrições pelos visitantes (Tabela 1), 60,83\% disseram sequer saber da existência dessas regras; entretanto, quando algumas delas foram listadas, houve mais aceitação do que rejeição. A maioria dos frequentadores entrevistados, 50 pessoas, considerou o fechamento dos espaços das $23 \mathrm{~h}$ às $06 \mathrm{~h}$ como positivo, pois seria uma forma de preservar o espaço de vândalos. Os que consideraram como negativo, 18 pessoas, argumentaram que essa estratégia faz o espaço perder seu caráter público ao tolher a liberdade das pessoas. 


\begin{tabular}{|c|c|c|c|c|c|c|}
\hline Regra/ restrição & Péssimo & Ruim & Indiferente & Bom & Ótimo & Total \\
\hline Fechamento de 00h às 06h & 5 & 13 & 5 & 42 & 8 & 73 \\
\hline Restição de acesso a ambulantes & 3 & 32 & 5 & 28 & 5 & 73 \\
\hline Restrição de acesso a animais & 4 & 25 & 5 & 33 & 6 & 73 \\
\hline Restrição às áreas gramadlas & 3 & 14 & 3 & 42 & 11 & 73 \\
\hline
\end{tabular}

Tabela 1 | Resultados da avaliação dos usuários a respeito das restrições e regras das áreas livres da Casa das Onze Janelas e do Forte do Castelo.

Fonte: Questionários aplicados pela autora, 2015

A única restrição considerada negativa pela maioria dos entrevistados (35 pessoas) é a que impede a entrada de vendedores ambulantes, pois poderia funcionar como uma oportunidade de trabalho para algumas pessoas, além de que seria conveniente ter opções de alimentação no espaço. Já os que consideraram positiva (33 pessoas), alegaram que a presença dos vendedores geraria sujeira e incômodo aos visitantes, interferindo na paisagem e não sendo compatível com o espaço.

A restrição a animais também foi vista majoritariamente como positiva (39 pessoas) pois, segundo os entrevistados, as pessoas não limpam os dejetos dos seus animais. Os animais também foram considerados incômodos e incompatíveis com o espaço. Segundo os que a julgaram como negativa (29 pessoas), a restrição tolhe a liberdade das pessoas e seria conveniente a presença de animais desde que os donos dos animais se responsabilizassem 
pela higiene do espaço.

A restrição às áreas gramadas foi considerada positiva por 53 entrevistados, por ser um modo de preservar o espaço, conservar a grama e não interferir na paisagem. Os 17 que desaprovaram a restrição consideraram que o contato com a grama é agradável e que a restrição tolhia a liberdade dos usuários, prejudicando a interação com o espaço e criando "áreas perdidas".

Foi questionado aos visitantes a sua concepção de espaço público e em seguida a sua impressão a respeito das áreas livres da COJFC como um espaço público. Ambas as questões eram abertas e, por isso, as respostas variaram. A impressão mais recorrente (aproximadamente 40\%) foi a de espaço público como "de acesso a todos", incluindo o fator da gratuidade. Alguns conceitos pouco definidos também foram citados pelos entrevistados como "espaços que permitem a interação entre pessoas e com o espaço", "espaços com diversidade de pessoas", "espaços de qualidade" e outros.

Sobre a percepção dos frequentadores entrevistados a respeito do objeto de estudo, $56,16 \%$ disseram que consideram as áreas livres da COJFC espaços públicos; 20,55\% disseram que não as consideravam públicas e 23,29\% disseram que era um espaço público com limitações, devido 
às regras de uso (Gráfico 1).

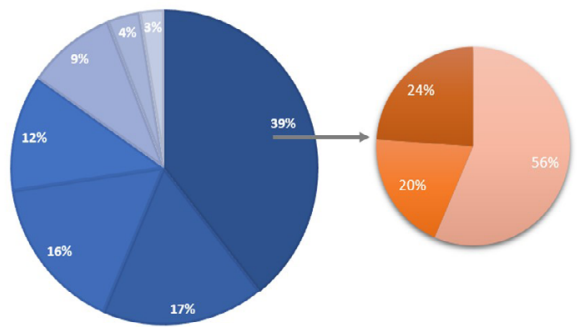

Legenda:

Acessível a todos indiscriminadamente (gratuito)

$\square$ O Espaço è pủblico

Espaço de qualidade/seguro/tranquilo

O Espaço é público com limitações

Permite a sensação de liberdade/lazer

O Espaço não é público

Outros

Permite a interação entre pessoas e com o espaço

É mantido com impostos/responsabilidade do poder público

Há diversidade de pessoas

Gráfico 1| Conceito de espaço público dos questionados e a opinião dos questionados sobre o caráter público do objeto de estudo

Fonte: Resultados da pesquisa

Destaca-se que $56,52 \%$ das pessoas que conceituaram espaço público como um espaço de acesso a todos, mesmo sabendo das restrições de acesso do espaço, consideraram as áreas livres da COJFC como espaço público. 19,57\% não o consideraram como espaço público e 23,91\% como espaço público limitado, ou seja, ao se tratar de um espaço aberto, integrado ao passeio público, mas ainda assim diferenciado dos espaços comumente encontrados na cidade. O espaço livre da COJFC e seu funcionamento geram 
contradições entre os usuários, que não conseguem compreender o seu caráter público/privado.

Nota-se que, quando aprovadas, as regras são sempre justificadas como estratégias de preservação dos espaços e, muitas vezes, como formas de proteger os espaços dos próprios frequentadores. A preocupação com uma possível poluição por parte dos vendedores ambulantes e donos de animais de estimação, e com um possível vandalismo, demonstra que se busca proteger o espaço de frequentadores que não prezariam por ele.

Uma parcela considerável dos entrevistados vê nas restrições uma limitação da liberdade individual dos visitantes, avaliando que há uma interferência na plena apropriação do espaço ao prejudicar a interação com o ambiente construído. Para alguns, a figura dos vigilantes e as suas estratégias de contato com os visitantes não demonstram a limitação do caráter público do espaço, ao se perceberem constantemente vigiados em suas ações. Daí a conceituação do objeto de estudo como espaços públicos com limitações.

Ainda que algumas restrições sejam vistas por uma minoria como um tolhimento à liberdade individual, elas parecem ser um custo válido para a maioria dos frequentadores, considerando o benefício de um espaço considerado de qualidade. A sensação de segurança constante no espa- 
ço - apesar de alguns relatos contrários — faz com que alguns visitantes vejam as restrições como um preço justo a pagar pelo bem-estar de que podem usufruir. Os espaços livres da COJFC são vistos como um oásis de segurança e tranquilidade em meio a uma região considerada altamente perigosa.

\section{Conclusões}

Como resultado da pesquisa de campo, nota-se que os espaços livres da COJFC apresentam um contraste com relação com o seu entorno. A sua integração com o espaço público somada às suas regras e restrições de uso geram uma confusão na percepção de alguns dos seus frequentadores no que diz respeito ao seu caráter público ou privado. Ainda assim, os espaços se mostram de grande importância na cidade de Belém, atraindo turistas e moradores de diversos bairros da cidade.

Segundo a pesquisa realizada, os espaços criados ou revitalizados pelo projeto, no que tange à sua utilização e estética, são aceitos por boa parte dos visitantes. A maioria dos frequentadores concorda com as regras que visam ao controle do uso e à preservação da imagem do espaço, legitimando, por exemplo, restrições a usos entendidos como incompatíveis com a paisagem. Os serviços de limpeza e segurança privados também contribuem para uma 
boa aceitação do espaço, considerando que, segundo os próprios entrevistados, as ruas adjacentes são perigosas e sujas.

Ainda assim, segundo os visitantes, as regras não seriam necessárias se houvesse uma garantia de que os frequentadores tivessem uma consciência da necessidade de preservação do espaço. Nota-se que há uma descrença na educação e no cuidado da população com os espaços urbanos, tornando aceitáveis regras às vezes entendidas como um tolhimento à liberdade individual, em prol da preservação do espaço coletivo. Os serviços de segurança e limpeza de qualidade e a existência de regras de uso e de acesso, que objetivam preservar o espaço dos próprios frequentadores, demonstram a necessidade latente de serviços públicos de qualidade e de políticas públicas de educação patrimonial, o que, em si, pode constituir outra perspectiva de análise.

\section{Referências}

Janelas e Casario da Rua Padre Champagnat. Vol. 4, Série Restauro. SECULT, 2006.

BELÉM, Vista aérea da Igreja da Sé (Catedral Metropolitana do Pará) - Belém. EDICARD - Editora Cultural Ltda. Data desconhecida. 1 cartão postal, color.

BRASIL. Plano Diretor da Reforma do Aparelho de Estado. 1995, 
p. 68. Disponível em: <www.bresserpereira.org.br>. Acesso em: 05 abr. 2015.

Ministério da Cultura. Portaria Minc $\mathbf{n}^{\circ} \mathbf{5 4}$, de 08 de maio de 2012. Homologa O Tombamento do Conjunto Arquitetônico, Urbanístico e Paisagístico dos Bairros da Cidade Velha e Campina, no Município de Belém, no Estado do Pará. Brasília.

CALDEIRA, Teresa P. do Rio. 2000. Cidade de Muros: Crime, Segregação e Cidadania em São Paulo. São Paulo: Editora 34/Edusp. 399 pp.

CASTELLS, Manuel; BORJA, Jordi. As cidades como atores políticos. Novos Estudos Cebrap, São Paulo, v. 1, n. 45, p.152-166, jul. 1996. Disponível em: <http://novosestudos.org.br/v1/files/uploads/ contents/79/20080626_as_cidades_como_atores.pdf >. Acesso em: 14 set. 2015.

CHOAY, Françoise. A alegoria do patrimônio. São Paulo: Unesp, 2001. CODEM, Cartografia. Belém, 2000.

DI PIETRO, Maria Sylvia Zanella. Direito Administrativo. 25 ed. São Paulo: Atlas, 2012.

HARVEY, David. A Produção Capitalista do Espaço. São Paulo: Annablume, 2005. 249 p.

LEITE, Rogerio P. Contra-usos da Cidade: Lugares e Espaço Público na Experiência Urbana Contemporânea. UNICAMP / UFS: Campinas / São Cristóvão, 2004.

SOUZA, Marcelo Lopes de. Fobópole: o medo generalizado e a militarização da questão urbana. São Paulo: Bertrand Brasil, 2008.

VAINER, Carlos B. Pátria, empresa e mercadoria. In: ARANTES, Otília; MARICATO, Ermínia; VAINER, Carlos. A cidade do pensamento único. Petrópolis: Vozes, 2000. p. 75-103. Disponível em: <http://labcs.ufsc.br/files/2011/12/16.-VAINER-C.B.-Pátria-empresa-e-mercadoria. pdf >. Acesso em: 14 set. 2015.

VARGAS, H. e CASTILHO, A. L. H. (org.). Intervenções em centros urbanos: objetivos, estratégias e resultados. São Paulo: Manole, 2006.

ZUKIN, Sharon. Paisagens Urbanas Pós-Modernas: Mapeando Cultura e Poder. In: ARANTES, Antônio A. (Org.). O Espaço da Diferença. Campinas: Papirus, 2000a. Cap. 4. p. 80-103. 
ZUKIN, Sharon. Paisagens do século XX: Notas sobre a mudança social e o espaço urbano. In: ARANTES, Antônio A. O Espaço da Diferença.

Campinas: Papirus, 2000b. Cap. 5. p. 104-115. 